\title{
O COTIDIANO DE ESCOLARES NASCIDOS PRÉ-TERMO: PERCEPÇÃO DE CRIANÇAS E FAMILIARES*
}

\author{
THE DAILY LIFE OF PRETERM BORN STUDENTS: \\ PERCEPTION OF CHILDREN AND THEIR FAMILIES
}

\author{
Maria Aparecida M. Gaíva ${ }^{1}$ \\ Maria das Graças C. Ferriani ${ }^{2}$
}

GAÍVA, M. A. M.; FERRIANI, M. G. C. O Cotidiano de Escolares Nascidos Pré-Termo: Percepção de Crianças e Familiares. Rev. Bras. Cresc. Desenv. Hum., São Paulo, 8 (1/2), 1998.

Resumo: Este é um estudo de cunho qualitativo cujo objetivo é analisar a percepção acerca da vida cotidiana de crianças nascidas pré-termo e hoje em idade escolar, segundo o olhar de mães/ familiares e destas crianças. Foram utilizados para esse fim a entrevista semi-estruturada, análise de documentos e a observação assistemática. A análise pautou-se na técnica de análise temática e foi realizada a partir da identificação de três Núcleos Temáticos: Saúde, Família e Escola. Os resultados revelam que as mães/familiares percebem a vida cotidiana de seu filho da seguinte forma: seus filhos são crianças saudáveis/normais. Algumas delas vão muito bem na escola, entretanto outras apresentam dificuldades de aprendizagem. Por outro lado, a maioria das crianças não apresenta problemas de saúde e a vida familiar emerge como aspecto fundamental para elas. O lazer e a religião também fazem parte de seu cotidiano. Para elas estudar é muito importante e a maioria não tem dificuldades na escola, mas os que têm assumem naturalmente o fato. Em relação à qualidade de vida podemos afirmar que todas as crianças têm atendidas suas necessidades de moradia, educação e lazer; no que concerne à saúde, algumas crianças apresentam limitações funcionais. Portanto nem todas as crianças estudadas vivem uma vida de qualidade.

Palavras-chaves: escolar; pré-termo; crianças; familiares.

\section{INTRODUÇÃO}

O trabalho cotidiano em uma Unidade de Terapia Intensiva Neonatal (UTIN) sempre nos despertou sentimentos de afetividade, especialmente por aqueles recém-nascidos com um alto grau de imaturidade, que na maioria das vezes, eram admitidos na unidade como inviáveis e, ao superar barreiras consideradas pelos profissionais como intransponíveis, começavam a fazer parte do mundo e a lutar pela vida de uma maneira muito especial, embora às vezes nossos conhecimentos técnicos não conseguissem compreender.
O convívio com as famílias desses pré-termo nos levou a refletir sobre alguns aspectos da assistência prestada, tanto na UTIN como no ambulatório. Inicialmente, nos preocupávamos muito mais com os procedimentos técnicos, ao invés de prestarmos um cuidado mais integral à criança e à unidade familiar; não tínhamos muito claro como estas crianças viviam após a alta.

A experiência acumulada no trabalho com a criança pré-termo hospitalizada ou em ambulatório levou-nos a problematizar como é o cotidiano e a qualidade de vida dessas crianças, principalmente em idade escolar.

* Resumo da Dissertação de Mestrado apresentada à Escola de Enfermagem de Ribeirão Preto da Universidade de São Paulo (GAIVA, 1997).

1 Profa. da Faculdade de Enfennagem e Nutrição da Universidade Federal do Mato Grosso, doutoranda do Programa Enfennagem e Saúde Pública da Escola de Enfennagem de Ribeirão Preto - ^Universidadede São Paulo. End: R, Gal. Valle, 431, ap. 1304, B. Bandeirantes, CEP 78010-100 - Cuiabá-MT - Tel.: (065) 624-5803

2 Profa. Titular da Escola de Enfenmagem de Ribeirão Preto - Universidade de São Paulo. 
A partir dessas considerações, definimos como objeto de estudo a vida cotidiana de crianças que nasceram pré-termo e que, hoje, se encontram em idade escolar.

Em relação à criança pré-termo em idade escolar, os estudos encontrados na literatura internacional são referentes aos seguintes aspectos: problemas de saúde e hospitalização, sequelas de complicações neonatais, problemas de aprendizado e comportamentais, estado de saúde de crianças de muito baixo peso ao nascer, dentre outros. Estas investigações em sua maioria são estudos longitudinais e prospectivos que traçam uma análise comparativa com crianças nascidas a termo.

A OMS considera pré-termo a criança nascida com menos de 37 semanas de gestação (WORLD HEALTH ORGANIZATION, 1961). No presente estudo, utilizaremos o termo prétermo para nos referir às crianças nascidas com idade gestacional menor de 37 semanas e peso menor de 2000 gramas.

O prognóstico dessas crianças está associado a algumas variáveis como assistência pré-natal e ao parto, idade gestacional e peso ao nascer, tipo e qualidade dos cuidados imediatos prestados, presença de complicações (FONTES, 1984).

Os recém-nascidos pré-termo e de baixo peso apresentam maiores riscos de morbi-mortalidade decorrente de sua imaturidade fisiológica e da terapêutica para manter sua estabilidade clínica. Aqueles sobreviventes têm ainda, maiores possibilidades de intercorrências em seu processo de crescimento e desenvolvimento, sejam de naturezabiológica, comportamental, emocional, social ou de aprendizagem, podendo necessitar, portanto, de seguimento a longo prazo e de serviços especializados na área da saúde e educação.

Os avanços no cuidado neonatal, nas últimas décadas, tornaram possível a maior sobrevida de bebés com peso e idade gestacional muito pequenas, reduzindo assim as taxas de mortalidade neonatal, mas resultando, algumas vezes, em aumento de crianças com sequelas incapacitantes. Decorrente das necessidades dessas crianças é preciso fazer um seguimento ("followup") multidisciplinar visando identificar e tratar precocemente as anormalidades e desvios do crescimento e desenvolvimento, além de monitorar a qualidade de vida dos sobreviventes.

A presente investigação tem como objetivo analisar a percepção acerca da vida cotidiana de crianças que foram pré-termo e que se encontram em idade escolar, segundo o olhar das mães/ familiares e destas crianças, visando a discutir se o fato de uma criança ser pré-termo afeta ou não a sua qualidade de vida.

\section{METODOLOGIA}

Este é um estudo de abordagem qualitativa em que o investigador busca, através dos dados descritivos da realidade em foco, ver como os sujeitos encaram a questão em estudo (LUDKE \& ANDRÉ, 1986).

O campo empírico dessa investigação situa-se na cidade de Cuiabá, capital do Estado de Mato Grosso. Os sujeitos da pesquisa foram 19 crianças nascidas pré-termo em idade escolar que estiveram internadas em uma UTIN de um Hospital Escola, cujas idades cronológicas variaram entre 6 a 11 anos, e 20 familiares (17 mães, 01 avó e 02 pais).

Os dados foram coletados em 2 etapas: na primeira, localizou-se as crianças através de um levantamento dos prontuários registrandose peso de nascimento, idade gestacional no nascimento, intercorrências do período neonatal, e o endereço da família; na segunda, foi utilizada a entrevista orientada por roteiro semiestruturado, com crianças e familiares. Um outro recurso utilizado foi a observação assistemática, com a finalidade de elucidar impressões.

Os resultados foram trabalhados a partir da técnica de análise de contéudo, modalidade análise temática, sistematizada por MINAYO (1994). Nesta técnica, após a organização dos dados, são identificados núcleos de sentido no conjunto dos dados para se processar a interpretação. Da análise de todas as entrevistas depreendemos 3 Núcleos Temático: saúde, família e escola.

\section{RESULTADOS E DISCUSSÃO}

Todas as crianças estudadas freqüentavam escola, desde classe de alfabetização até a $5^{\mathrm{a}}$ série do primeiro grau; uma delas freqüentava o ensino especial para deficiente visual. No que diz respeito à saúde atual, duas crianças, fazem acompanhamento médico (neurologista e homeopata), uma por epilepsia e outra por disritimia, sete crianças tinham adoecido nos últimos meses, sendo que duas por hepatite $\mathrm{A}$, uma por sinusite, uma por caxuinba e uma por bronquite, amigdalite e crise convulsiva e uma por varicela. Só há um relato de internação nesse período, que se deu após acidente automobilístico. Onze crianças entrevistadas, possuíam algum tipo de plano ou seguro de saúde.

Dos familiares entrevistados, 09 mães e 01 avó tinham o primeiro grau, 04 o segundo grau e 04 o nível universitário; 09 delas trabalhavam fora 
do lar, contribuindo para o sustento da família. A renda mensal variou de 02 a 20 salários mínimos ${ }^{3}$. Quanto a situação marital 03 mães não tinham cônjuge ou companheiro. São famílias relativamente pequenas, em média com 04 componentes. Em relação às condições de moradia, somente 02 famílias pagavam aluguel e o restante possuíam casa própria.

\section{Núcleo Temático - SA UDE}

Nesse núcleo foram detectados 3 subtemas: Crescimento e desenvolvimento; Alirnentação e Saúde atual.

\section{Subtema 1- Crescimento e desenvolvimento}

Tanto na fala das mães como das crianças a prematuridade está associada ao tamanho menor e a fragilidade, portanto, necessitando de maiores cuidados e proteção. A percepção que as crianças têm acerca da prematuridade foram adquiridas a partir da percepção de sua família, confirmando o papel do meio familiar na assimilação de alguns conceitos emitidos pelas crianças. cepção:

Eis algumas falas que expressam essa per-

"Ele sempre foi magrinho, pequeno... “ (Mãe Criança P)

“...é difícil prá cuidar: ...tem que ter um cuidado maior." (Mãe Criança C)

"Minha mãe falava que era pequena, baixo peso." (Criança D)

“... nasci de 6 meses e podia ter morrido se não tivesse muito cuidado quando era pequeno." (Criança S)

As mães expressam as características físicas dessas crianças ao nascer, como pequenas, baixinhas e magrinhas, diferentemente dos filhos nascidos a termo. Essa associação de prematuridade à dimensão do crescirnento, por parte das mães, também foi encontrada em estudo realizado por JAVORSKI (1997).

Mas à medida que essas crianças vão crescendo e adquirindo peso, passam a aproximar-se da aparência de outras crianças; a preocupação com a prematuidade diminui e as mães ficam mais seguras, conforme registramos nas falas:

"Enquanto ele não começou a engordar, não começou a ficar parecendo os outros meninos, sabe não fiquei tranqüila.” (Mãe Criança L)

"conforme ele ia crescendo eu esqueci que ele era pré-termo.” (Mãe Criança M)

Em virtude das características e da fragilidade dessas crianças, muitas mães alegam ter medo de cuidar do filho, após a alta, delegando os cuidados ao pai, avó e pessoal de enfermagem.

"Nunca tive coragem de dar banho, até mamãe também, com medo de machucar, contratamos uma enfermeira para dar banho..." (Mãe Criança T)

O medo de cuidar do filho no domicílio, após alta, também foi encontrado por GOMES (1992) ao ouvir mães que estavam vivendo a experiência de ter o filho pré-termo em uma UTIN.

Observamos que não só o aspecto fisico preocupa a família, pois as mães exteriorizam também seu medo da criança ter complicações graves; a insegurança é muito grande, chegando a interferir nos hábitos e rotinas de todos os membros da família.

“...eu tinha medo de dar alguma coisa () doença, e eu não saber cuidar.” (Mãe Criança Q)

“...de noite aqui você pensa que eu dormia assim tranqüila, eu acordava a noite e pensava será que ele não teve algum problema? Eu levantava e ia verificar se ele estava vivo mesmo, assim com medo.” (Mãe Criança L)

Um outro aspecto percebido pelas mães refere-se ao fato do filho também necessitar de maior atenção e carinho. A fragilidade estaria ligada não só ao aspecto fisico, mas também ao emocional. Essas crianças necessitam de uma proteção maior e isso faz com que as mães as tratem de forma diferenciada em relação aos irmãos.

"Mas o carinho e o trabalho com ela é dobrado, então eu fazia de tudo, era diferente. Os outros (irmãos) cobravam, por que você tem mais carinho com a J?. Eu explicava pré eles que ela era pré-termo e que precisava ter mais carinho." (Mãe Criança J)

Percebemos também que algumas mães, principalmente as de estrato social menos favorecido, dão ao filho pré-termo um tratamento diferenciado, mesmo depois de crescido, caracterizado como superproteção, a qual já foi enfocada por vários autores (BRAZELTON, 1988; WALKER, 1989; MORAES, 1995). Esse aspecto é expresso nas seguintes falas:

"Ela é o xodó da rua, os vizinhos chamam ela de passarinho, ainda é esse carinho mesmo que ela cresceu.” (Mãe Criança J) Criança M)

"Ele sempre fòi muito mimado." (Mãe

Para os pais de um bebé pré-termo, seu filho é uma criança "diferente" nos primeiros anos e, por isso, tendem a protegê-lo com uma atenção exagerada. Às vezes, mesmo depois que a crian-

3 Salário mínimo vigente na época R\$ 120,00. 
ça tenha mais idade, eles continuam a fazer tudo por ela, sem perceber que podem estar interferindo no desenvolvimento da mesma. Para BRAZELTON (1988) o excesso de carinho e atenção por parte dos pais é um comportamento natural e esperado, durante a fase inicial de desamparo do bebê. No entanto, a superproteção pode afetar o seu potencial para o desenvolvimento da autonomia, que por sua vez pode ter conseqüências em sua qualidade de vida.

Quando se referem ao desenvolvimento do filho, as mães lembram que apesar de ele ter sido pré-termo, a criança teve um desenvolvimento normal; algumas chegam a afirmar que a criança teve algumas fases desse desenvolvimento mais acelerado.

“...aos seis meses ela já estava sentando, ai andou tudo normal, falar, falou cedo também." (Mãe Criança H)

"Apesar dela ser pré-termo ela foi uma menina que se desenvolveu bem.” (Avó Criança F)

O fato de uma criança nascer pré-termo não quer dizer que ela terá problemas graves e alterações neurológicas. Os danos cerebrais dependerão do tamanho, estágio de maturidade, condições fetais, atendimento imediato depois do parto e cuidados neonatais. Existem evidências hoje de que $70 \%$ dos bebés pré-termo terão desenvolvimento normal (BRAZELTON, 1988). Estudo realizado por SOBOLEWSKI e col. (1996), com crianças brasileiras de baixo peso ao nascer, confirmam os dados acima, pois ao final de dois anos de acompanhamento $70 \%$ das crianças foram consideradas com desenvolvimentos normais.

Observamos, durante as entrevistas, que as mães sentiam uma necessidade muito grande de ter a certeza de que seu filho não corre mais riscos, afirmando a todo momento a normalidade do filho: ele tem crescimento normal, se desenvolveu rápido, ele é uma criança normal.

As mães ao fazerem essa afirmação estão se referindo à normalidade como um parâmetro fisiológico, qual seja, é normal a criança que nasce com peso acima de 2500 gramas; para elas a criança pré-termo não é anormal e sim um normal "diferente", que por esse motivo requer cuidados especiais, mas isso não o torna patológico.

Os pais expressam preocupações ligadas ao futuro do filho pré-termo, as quais são associadas não somente ao crescimento físico e complicações, mas principalmente aos aspectos emocionais e psicológicos da criança.

"A preocupação maior hoje da gente em relação ao futuro é que ele possa ter algum distúrbio mesmo dessa ordem, neurológica, do lado da psique do emocional...” (Pai Criança R)
“A preocupação é a maneira como ela se comporta, irritada, esse temperamento dela, essa duvida que eu não sei se mais tarde pode, sei lá, né.” (Mãe Criança E)

Nos últimos anos, uma grande variedade de distúrbios ligados ao comportamento cognitivo e motor associados à prematuridade foram reconhecidos. Um dos estudos realizados nesta área é o de PHAROAH e col. (1994), que avaliou a prevalência de distúrbios de comportamento em crianças com menos de 2000 gramas, através de questionários que foram respondidos por pais e professores, avaliando os distúrbios de conduta (agressividade, desobediência, comportamento anti-social) e os distúrbios emocionais (ansiedade, tristeza dentre outros). Os resultados mostraram que $36 \%$ das crianças tinham algum tipo de distúrbio de comportamento segundo os pais e para os professores $27 \%$ delas. Para esses autores é possível que, a longo prazo, as crianças de baixo peso venham a desenvolver problemas psiquiátricos, o que faz com que essas crianças necessitem de seguimento prolongado.

O crescimento e desenvolvimento do filho pré-termo trouxe para a família muitas preocupações; desde aquelas ligadas ao crescimento físico até aos aspectos emocionais e psicológicos da criança.

\section{Sub-tema 2 - Alimentação}

O aleitamento materno surge nos discursos maternos de maneira forte e, principalmente, traz à tona algumas dificuldades que essas mães enfrentaram no decorrer da hospitalização do filho, indo contra a representação de que para amamentar basta querer, ou seja, depende exclusivamente da mãe. Concordamos com JAVORSKI (1997) ao afirmar que amamentar uma criança prétermo não depende só da mãe, uma vez que existem fatores outros que podem interferir nessa decisão, como é o caso da imaturidade da coordenação entre a sucção, a deglutição e a respiração, do estresse materno e do longo período de hospitalização da criança; todos esses fatores podem dificultar a manutenção da amarnentacão.

As falas das mães, mesmo muitos anos após o nascimento do filho algumas até onze anos, como é o caso da mãe da criança S que relembra a amamentação do filho como se ela tivesse passado por isso há pouco tempo, repetem bem o esforço dispendido por ela e até pelo pai, para assegurar o leite materno ao filho.

"...eu amamentei uma menina por um ano para meu leite não secar, doava leite pro hospital, eu bebia meu leite, ele (pai) bebia, tinha uma outra menininha da vizinha que bebia.” (Mãe Criança S) 
Nas últimas décadas, o aleitamento materno vem sendo revalorizado e o ato tem sido simbolizado como uma demonstração de apego e dedicação materna. E nós, enquanto profissionais, mesmo que de forma inconsciente, acabamos por demonstrar essa visão para as famílias com as quais lidamos.

"Teve um tempo, no início teve aquela coisa dela não querer mamar; teve aquela coisa em cima de mim que eu não queria dar mamar; ... porque eu sabia que não era aquilo que eles (família) estavam falando, estavam julgando, porque eu sabia, conversei com vários médicos e eles falavam prá mim que não era questão de eu querer, era questão de que ela não conseguia sugar" (Mãe Criança C)

JAVORSKI (1997), em estudo com mães que estavam passando pela experiência de amamentar um filho pré-termo em unidade de cuidado canguru, verificou a relação entre maternidade e amamentação; para elas a mãe que amamenta é uma boa mãe, é perfeita, não é negligente e se sente mais mãe ao amamentar.

As mães que entrevistamos associam as dificuldades alimentares das crianças ao fato delas terem sido pré-termo.

"Ele só é sensivel com a alimentação, qualquer coisa mais gordurosa, mais temperada ele sente.” (Mãe Criança S)

“... a única coisa dela é que ela não tem aquela coisa de comer, se você ver a comidinha dela, tem dias que ela come carne, uma saladinha, mas tem dias que só arroz, sem verdura, sem feijão, adora farofa.” (Mãe Criança J)

“...também ele é ruim pré comer, ele sempre magrinho.” (Mãe Criança G)

Para as mães, o filho pré-termo se diferencia também pelas características alimentares, pois desde do início da alimentação tem dificuldades.

\section{Sub-tema 3 - Saúde atual}

Embora a maioria das mães diz que os filhos são saudáveis, apreendemos pelos relatos e observações que algumas crianças apresentam, atualmente, problemas de saúde diagnosticados, sendo acompanhadas por especialistas. Alguns desses problemas podem estar associados a prematuridade e a terapêutica. As mães descrevem problemas visuais, neurológicos e cardíaco:

"A saúde dele só aquela internação por causa dos abcessos e o problema de coração que ele teve, mas não prejudica ele.” (Mãe Criança Q)

"...o problema dele é a vista..." (criança estrábica com déficit visual)... ele diz que às vezes enxerga dois, diz também que a vista dele não tá ajudando muito...” (Mãe Criança N) “...só fomos perceber que ele não enxergava com s meses.. já operou de uma vista e a gente viu que não teve resultado... teve as crises, ainda tem, é epilepsia, até hoje toma remédio e acompanha com a neurologista.” (Mãe Criança P)

De modo geral, os problemas de saúde relatados pelas mães são, em sua maioria, doenças comuns da infância, sem maior gravidade quando tratadas adequadamente.

"Ela é saudável, às vezes tem uma gripinha”. (Mãe Criança O)

"Ela tinha é bronquite... (Mãe Criança $\mathrm{H}$ )

Os problemas de saúde mais frequentemente relatados foram os do aparelho respiratório, levando, algumas vezes, a internações hospitalares.

A única criança que apresenta intercorrência incapacitante severa (criança $P$ ) não quis falar sobre o assunto. Ele é cego, mas durante sua fala nos disse enxergar vultos quando está perto, mas em seguida mudou de assunto, numa atitude clara de não querer falar de algo que o incomoda. Tanto a avó como os pais afirmaram que a criança tem estado preocupada com a doença e, ultimamente, tem se apegado à religião em busca de cura.

Todas as crianças entrevistadas tiveram acesso a um programa de seguimento, mas somente uma permaneceu no referido programa até a idade preconizada (7 anos) e outras duas até a idade pré-escolar (5 anos); o restante das crianças freqüentaram o programa apenas por alguns meses. Convém lembrar que algumas famílias possuem una situação econômica mais favoráveL além do que metade delas têm acesso a atendimento médico através de plano ou seguro de saúde, o que lhes dá a oportunidade de procurar assistência em outros serviços que não o hospital escola.

Considerando a qualidade de vida relacionada à saúde, quando retomamos a história de vida dessas crianças e comparamos com seu estado de saúde atual, percebemos que a qualidade de vida das mesmas hoje pode ter sido influenciada diretamente pelas condições de nascimento e estrato social da família. Tomando como referência os dados de nascimento das crianças, podemos afirmar que praticamente todas as crianças que hoje apresentam problemas de saúde tiveram um índice de Apgar baixo no primeiro e quinto minutos, idade gestacional no nascimento em torno de 32 a 33 semanas e algumas crianças tinham peso de nascimento menor de 1500 gramas, necessitando de um longo tempo de internação.

Esses achados corroboram aqueles da literatura apontando que o prognóstico das crianças pré-termo sofre influência de variáveis como idade gestacional, peso ao nascer e complicações apresentadas, dentre outros (FONTES, 1984; HACK, 1993). 


\section{Núcleo Temático 2 - FAMÍLIA}

\section{Sub-tema I - Revivendo a gravidez e o nascimento do filho pré-termo}

Apesar dos filhos estarem em idade escolar, as mães ainda traziam muito viva na memória falos da gestação e do nascimento. A gravidez é descrita como difícil e problemática desde o início, sendo considerada de risco, tanto para a mãe, como para o filho. A mãe da criança Q deixa claro como foi esse período:

“...ele (médico) falou, olha você vai sofrer um pouco, mas agora não tem mais jeito já está grávida, agora vamos ver o que vai dar, $e$ desse dia em diante a vida, a minha e de minha familia mudou, né...eu lava com 6 meses e tive que internar, internar assim às pressas né. A pressão tava muito alta, fiquei correndo risco de vida, início de ecl^ampsia. Tive que internar e ficar internada um tempo até ele nascer:"

O nascimento de um filho pré-termo e o conviver com a internação em uma UTIN geram nos pais sentimentos de revolta, culpa, angústia, tristeza, medos e esperança, os quais também foram encontrados em vários outros estudos com mães que tiveram filhos pré-termo (GOMES, 1992; LAMY, 1995; JAVORSKI, 1997). As falas seguintes retratam esse aspecto. Criança G).

“.. foi triste né porque sofri muito” (Mãe

"Eu naquela época eu até me assustei. Eu nunca tinha visto uma criança pré-termo, quando nasceu ele até assustei, pequeninho. Será que é meu filho? (Mãe Criança N)

"...mas a sensação de culpa porque você não foi capaz, isso ai é muito triste, ela você carrega muito tempo... quando eu via na rua aquelas mulheres, qualquer mulher com aquela barrigona grande, eu olhava e sentia, eu não fui capaz, pré mim elas (filhas) representavam uma impotência minha.” (Mãe Crianças A/B).

A representação de que a mulher nasceu para ser mãe e dar a luz a bebês robustos ainda é muito forte, o que vem reforçar a culpa, impotência e o sofrimento sentido pelas mães de pré-termo. Algumas delas até duvidam que o pré-termo seja seu mesmo, talvez na tentativa de minimizar estes sentimentos.

\section{Sub-tema 2 - A ida para casa com o filho pré-termo}

A alta é o momento mais esperado para os pais de um bebé pré-termo, mas também o mais temido. Não importa quanta experiência tenham tido no manuseio do filho, esse período será problemático para os pais, pois estarão angustiados e muito assustados, já que agora serão os responsá- veis pela segurança do bebê e não mais os profissionais do hospital. Dentro da rede informal de apoio, os pais buscam ajuda entre os membros da família e dividem não só as tarefas do cuidar, mas também as preocupações.

"Todo mundo ajudava, meus filhos, noras. Entrou todo mundo para ajudar." (Mãe Criança N)

"Quando veio para casa... todos os irmãos ajudaram a cuidar.” (Mãe Criança O)

O estereotipo cultural da maternidade ainda está muito presente em nossa sociedade, e apesar das transformações ocorridas na estrutura familiar, o pai tem um papel subsidiário à mãe no relacionamento e no cuidado direto do filho; ele é aquele que dá o apoio financeiro.

"Eu cuidei dela sozinha...meu marido trabalhando fora.. . " (Mãe Criança J)

"Cuidei dela sozinha, meu marido quase não ajudava, que ele não tem tempo." (Mãe Criança G)

Independentemente da cultura, a responsabilidade do cuidado e educação dos filhos, no âmbito da família, destina-se primordialrnente às mulheres (PARKER, 1991).

Apesar da hegemonia do papel masculino ainda ser acentuada na sociedade contemporânea, mudanças vêm ocorrendo em relação aos papéis desempenhados no público e no privado. Em uma das entrevistas, isso fica bem evidente.

"Quando ela nasceu eu (pai) entrei de licença especial. Os três meses que eu estava de licença fiquei aqui em casa ajudando ela (mãe) no dia a dia, e em cuidar da nenen também" (Pai Criança H).

Percebe-se claramente nesse caso que o pai passa a atuar em uma área até então considerada de competência da mulher. Para ROMANELLI (1991) o fato do homem atuar na produção de valores de uso no âmbito do privado, estabelece novas formas de socialização na família e torna o relacionamento entre pai e filhos mais próximo.

Alguns aspectos que não foram evidenciados nas falas das mães emergem nitidamente nos discursos das crianças. A religiosidade parece ser um fato importante na vida familiar dessas crianças, já que surge em praticamente todas as falas das crianças de mais idade:

“...aos domingos vou na igreja...” (Crian-

"Sou adventista, no sábado não saio, a igreja não permite, fico em casa..." (Criança S).

Sabemos da influência que a família tem nessa idade quanto à religiosidade, ou seja, normalmente a criança acompanha os pais à igreja como mais uma obrigação familiar e não uma opção sua, no entanto, percebe-se que quando essas crianças falain das atividades religiosas, estão 
falando delas; inclusive as mães relatam não ter influenciado em suas escolhas para freqüentar ou não um curso religioso/catequese.

O lazer foi outro aspecto não presenciado nos discursos das mães, mas todas as crianças ao contar seu dia a dia traziam atividades de recreação. Se considerarmos a TV como lazer, ela está presente em todas as falas, independentemente do estrato social da criança.

"Levanto, brinco, assisto TV." (Criança G)

"A tardinha faço as tarefas, assisto TV, desenhos e novela Zazá" (Criança O).

Esse dado vem ao encontro dos resultados da pesquisa realizada por MORAES (1994), que ao analisar os hábitos de lazer infantil, detectou que $93 \%$ das crianças independente da idade, sexo e classe social vêem TV no dia a dia.

O lazer das crianças de um estrato social mais favorecido economicamente está ligado aos esportes coletivos, clubes e vidro garne. Por outro lado, aquelas de estrato social menos favorecido utilizam-se das brincadeiras coletivas com irmãos ou amigos, como brincar de boneca, escolinha, jogar bola, dentre outras. Essas crianças relatam também como atividade de lazer ir à feira livre com o pai e frequentar a igreja.

\section{Núcleo Temático 3 - ESCOLA}

\section{Sub-tema I - Função da escola}

A criança em idade escolar inicia uma etapa da vida em que sua rotina diária é ampliada pela inclusão da escola e de novos companheiros para brincar e estudar. É a partir dos 6 a 7 anos que a criança principia a construir seu projeto de ser, fundamentado na expectativa familiar e ampliado pelo contato com outras experiências no meio social e escolar.

Ao falarem da educação dos filhos, as mães deixam transparecer a idéia de que a escola é praticamente o único meio de ascensão social e melhoria de vida.

"Ah quero o melhor prá ela, quero que ela estude, principalmente o estudo, porque a gente que é pobre e não tem como dar uma riqueza material pré ela, faz de tudo pré ela estudar..." (Avó Criança F)

“...quero que ela estude e seja alguém na vida..." (Mãe Criança O)

Em relação ao nível do ensino, percebemos que existe por parte das mães uma idéia pré concebida de que a escola particular é a melhor escola e que a éscola pública tem um ensino fraco. Apesar desse conceito, nem as mães que têm filhos em escolas particulares (Mãe da criança D) e nem aquelas que tem crianças em escola públi- ca (Mãe da criança Q) estão satisfeitos com o ensino e querem trocar os filhos de escola.

“...ele estava indo bem, mas ai teve a greve e f cou muito tempo parado, quase dois meses de greve. ..." (Mãe Criança Q)

"acho a escola um pouco fraca por ser particular...” (Mãe Criança D)

Não existe escola ideal, devemos ter claro que a melhor escola é aquela que preenche as expectativas e os planos que as famílias têm acerca dos filhos.

A escola também assume na vida das crianças uma importância semelhante à descrita pelas mães, isso é percebido, quando elas descrevem suas atividades, colocando sempre a escola em primeiro lugar e o estudo como uma atividade que gostam de fazer.

“... eu gosto de estudar. ..” (Criança C)

"ir a escola eu gosto mais..." (Criança E)

“...minhas notas são boas” (Crianca L)

Algumas mães também enfatizam o desempenho da criança em seus discursos.

"Na escola nunca deu problema, mandar fazer tarefas, estudar, as notas dela são sempre boas, as professoras sempre elogiam ela, sempre tá adiantada" (Mãe Criança D)

"...nunca teve problema na escola, sempre teve nota boa...” (Avó Criança F)

A educação/escola foi uma preocupação presente tanto nos discursos maternos como das crianças; o bom desempenho do filho na escola foi muito valorizado pelas mães. Acreditamos que essa valorização esteja associada à representação de que a criança pré-termo está sujeita a danos neurológicos e que o fato de ir bem na escola significabom prognóstico para a saúde futura.

\section{Sub-tema 2 - Dificuldades escolares}

Um outro aspecto que se destacou nas falas das mães e das crianças refere-se às dificuldades para ficar na escola, expressas pelo chorar e comportamento de recusa na hora de ir para a escola.

"No inicio da escola, no pré ela chorava, até a la série ela era assim, a professora saia para ir à sala dos professores e ela ia junto...” (Mãe Criança C)

"...quando eu era menor eu chorava quando ia começar as aulas ai minha mãe precisava ir lá e falar com a professora. Mas desde do ano passado me acostumei e não choro mais." (Criança B)

Em todo processo de desenvolvimento a criança passa por algumas situações de transição que podem ser consideradas como eventos estressantes, como é o caso do ingresso à escola, que pode ter efeitos negativos sobre o comportamento. Devemos considerar também que o grau 
de adaptação é variável entre crianças, algumas sentem mais que outras.

LIMA e col. ( 1987) afirmam que aquelas crianças que tenham sido previamente preparadas para a socialização secundária e que apresentam amadurecimento intelectual, emocional e físico suficiente para aceitar as modificações em sua rotina de vida com o ingresso na escola, não terão dificuldades de adaptação.

Uma outra questão relacionada à aprendizagem escolar que esteve muito presente nas falas de mães e crianças foram as chamadas "dificuldades de aprendizagem” ou "mal rendimento escolar”. Quando falamos em dificuldades de aprendizagem, nesse estudo, estamos nos referindo à criança que tem rendimento escolar inferior, bem como aquelas que tem muita dificuldade em concluir uma série, necessitando freqüentar aulas de recuperação e/ou reforço; não necessariamente são crianças que têm reprovações em seu histórico escolar. A prematuridade é abordada na literatura em geral como um fator de risco para as dificuldades de aprendizagem (LIMA e col., 1987; BRANDT e col. 1992; LOW e col. 1992; ROUSSOUNIS e col. 1993).

Ao analisarmos os discursos das crianças, percebemos que elas não demonstram nenhum constrangimento em assumir suas dificuldades em aprender, embora saibam o quanto seus pais esperam por seu sucesso estudantil.

"Minhas notas nesse bimestre fui meio caído, português tirei 4, vou fazer recuperação, no teste tirei 6, não fiquei de recuperação em mais nada....Nunca reprovei." (Criança S)

"Nas últimas provas tirei nota vermelha, mas já recuperei." (Criança T)

Apesar das dificuldades de aprendizagem, essas crianças nunca tiveram nenhuma reprovação e estão na série esperada para a idade; talvez por esse fato não estejam ainda estigmatizadas nem na escola e nem na família, o que se torna muito comum entre as crianças portadoras de dificuldades de aprendizagem, que começam a ser marginalizadas dentro da própria família e continuam a ser discriminadas na escola.

A criança $\mathrm{T}$ pertence a uma família com uma melhor condição socioeconômica, estuda em uma escola particular e os pais têm nível superior de escolaridade; entretanto, enfrenta problemas de aprendizado desde o início da escolarização, como podemos ver na fala da mãe:

"...fez a classe de alfabetização (CA) por duas vezes, porque o diretor chamou e perguntou o que eu achava dele fazer outra vez o CA, porque ele era muito imaturo, ai eu concordei." (Mãe Criança T)
Existe uma diferença no tratamento das dificuldades de aprendizagem de acordo com o nível socioeconômico da família. As mães que pertencem a um estrato social mais desfavorecido economicamente buscam resolver esse problema dentro da própria escola e com ajuda da professora; as famílias que possuem facilidades econômicas vão buscar auxílio fora da escola (aulas particulares, pediatras, neurologistas, psicólogo etc).

Um outro recurso utilizado pelas famílias nos casos de dificuldades ou baixo rendimento escolar dos filhos é o uso das aulas de reforço. Esse recurso tem sido também utilizado pelas famílias que nao dispõem de tempo para acompanhar os deveres escolares de seus filhos, independente destes terem ou não dificuldades.

Tomando por base os dados acima discutidos, podemos afirmar que o acesso à educação, enquanto um direito de cidadania, todas as crianças a têm, pois estão matriculadas em escolas de primeiro grau públicas ou privadas; algumas têm acesso ao ensino especial como é o caso da criança P. Outras crianças dispõem de formas complementares de educação como aulas de língua. Observamos também que há uma uma diferenciação social desse acesso, já que as de maior poder aquisitivo estão em escolas particulares e as de menor nas escolas públicas.

\section{CONSIDERAÇÕES FINAIS}

Esta investigação possibilitou apreender nas falas das mães/familiares sentimentos contraditórios acerca da vida cotidiana do filho hoje. Em alguns momentos consideram que, apesar de pré-termo, ele é uma criança normal, mas em outros ele é considerado uma criança "diferente”.

Um outro aspecto que evidencia essas contradições foi expresso em forma de preocupações com a vida futura dos filhos. Mesmo considerando os filhos como crianças normais, como qualquer outra criança, seus pais preocupam-se com o aparecimento de problemas futuros ligados principalmente aos aspectos psicológico e emocional dessas crianças.

Em nosso entender essas contradições e negações são decorrentes da representação que essas famílias possuem de prematuridade, ou seja, de que a criança que nasce pré-termo é uma criança diferente/anormal. Essa representação é muito evidente, principalmente no início da vida da criança, mas perdura em algumas famílias até hoje. A percepção de prematuridade que as famílias têm faz com que assumam frente ao filho comportamentos de superproteção. Ao olharmos ainda a vida cotidiana na perspectiva das mães/ 
familiares, observamos que para elas os filhos são crianças saudáveis, algumas crianças têm excelente desempenho escolar, enquanto outras têm dificuldades de aprendizagem.

Detendo-nos nas falas das crianças percebe-se que elas têm conhecimento que nasceram pré-termo, além de ter percepção semelhante a que a família possui acerca da prematuridade. As crianças ao relatarem suas percepções acerca da vida cotidiana trazem como aspectos fundamentais a vida familiar, a escola, o lazer e a religião, os quais divergem um pouco da percepção de suas famílias.

Observamos que as famílias utilizam estratégias diferentes para lidar com as dificuldades que os filhos pré-termo apresentam na idade escolar. Em relação à saúde, as famílias que possuem situação econômica mais favorecida procuram profissionais ligados à rede privada ou conveniada de saúde, quando seus filhos apresentam problemas. Por outro lado, as famílias de baixa renda recorrem ao programa de seguimento ou ao posto de saúde mais próximo de sua residência. Esse comportamento legitima o modelo de atenção vigente, no qual as ações são focais e centradas na doença.

No que diz respeito à questão educacional, observamos que as famílias utilizam estratégias diferentes para lidar com as dificuldades de aprendizagem de seus filhos: aquelas de melhores condições socioeconômicas procuram ajuda junto aos profissionais das mais diversas especialidades (neurologista, homeopata, psicólogo, te- rapeuta ocupacional), bem como aulas de reforço contínuas em escola particular; aquelas de menor poder aquisitivo recorrein à própria escola que 0 filho estuda, na tentativa de solucionar o problema apresentado.

No que diz respeito à qualidade de vida podemos considerar que todas as crianças estudadas tiveram acesso à moradia, saneamento, bens de consumo individual e coletivo, educação, seja ela pública ou privada, e lazer, embora houvesse variações segundo o estrato social. Mas nem todas as crianças foram atendidas em suas necessidades de saúde.

As crianças estudadas não apresentaram limitações funcionais graves, exceto uma delas. No entanto, algumas crianças apresentam autoestima diminuída em virtude de problemas de saúde e outras convivem com dificuldades de aprendizagem.

Podemos dizer pelos resultados obtido que a prematuridade não pode ser vista, enquanto um fator unicausal que vai determinar a qualidade de vida dessas crianças, mas que fatores como as condições socioeconômicas, ambientais e culturais em que estas vivem interferem diretamente. Ademais, considerando esses fatores e o que apregoa o Estatuto da Criança e do Adolescente, não podemos afirmar que todas as crianças desse estudo vivem uma vida de qualidade, já que a qualidade de vida dessas não está ligada somente às condições de nascimento, mas também às condições ambientais e emocionais presentes em todo o Processo de seu desenvolvimento.

\begin{abstract}
This is a qualitative study whose objective was to analyze the perception regarding the daily life of prematurely born children now of school age according to the opinion of the mothers/ relatives and the children themselves. Semistructured interviews, document analysis and asystematic observations were the procedures used. The analysis was based on the technique of thematic analysis and was carried out starting from the identification of three Thematic Nuclei: Health, Family and School. The results revealed that the mothers/relatives perceive the daily life of their children as follows: their children are healthy/normal, some ofthem do very well at school, whereas others have learning difficulties. The children perceive themselves as any other children, most of them have no health problems and their family life emerges as a fundamental aspect. Leisure and religion are also part oftheir daily life. Studying is very important for them and most have no difficuties at school, but those who do experience difficulties consider this fact to be natural. Finally? with respect to the quality of life, it is possible to state that all children are well provided for in terms of their housing, education and leisure needs, but not all of them receive the health care they need; in addition, some children present functional limitations. Thus, not all the children studied live a life of quality.
\end{abstract}

Key-words: students, premature, children, family. 


\section{REFERÊNCIAS BIBLIOGRÁFICAS}

BRANDT, P. et al. Learning and behavioralemotional problems of chindren born preterm at second grade. J. Pediatx Psychol., 17(3): $291-311,1992$.

BRAZELTON, B. T. O desenvolvimento do apego. Uma familia em formação. Porto Alegre, Artes Médicas, 1988.

FONTES, J. A. S. Prematuridade: aspectos pediatricos. In: FONTES, J.A S. Perinatologia social. São Paulo, Fundo editorial BYK Procienix, 1984. Cap.28. p.284-288.

GOMES, M. M. F. Ter o filho intemado na unidade de terapia intensiva neonatal: o significado para os pais. São Paulo, 1992. [Dissertação de Mestrado Escola Paulista de Medicina].

HACK, M. O êxito do tratamento intensivo neonatal. In: KLAUS, M.H.; FANAROFF, A. A. Alto risco em neonatologia. $4^{\text {a }}$ ed. Rio de Janeiro, Guanabara Koogan, 1993. Cap.18, p. 339-344.

JAVORSKI, M. Os significados do aleitamento materno para mães de pré-termo em cuidado canguru. Ribeirão Preto, 1997. [Dissertação de Mestrado Escola de Enfermagem de Ribeirão Preto, Universidade de São Paulo].

LAMY, Z. C. Estudo das situações vivenciadas por pais de recém-nascidos internados em unidade de terapia intensiva neonatal. Rio de Janeiro, 1995. [Dissertação de Mestrado - Fundação Oswaldo Cruz].

LIMA, G. Z. et al. A criança na escola. In: MARCONDES, E. Pediatria básica. $7^{\mathrm{a}}$ ed. São Paulo, Sarvier, 1987. v. 1, p. 69-73.

LOW, J. A. et al. Association of intrauterine fetal growth retardation and learning deficits at age 9 to 11 years. Am. J. Obstet. Gynecol., 167(ó): 1499-1505, 1992.
LUDKE, M.; ANDRÉ, M. E. D. A. Pesquisa em educação: abordagem qualitativa. São Paulo, EPU, 1986.

MINAYO, M. C. d. S. O desafio do conhecimento: pesquisa qualitativa em saúde. $3^{\mathrm{a}}$ ed. São Paulo, Hucitec - Abrasco, 1994.

MORAES, M. C. L. d. O retardo de crescimento intrauterino (prematuridade) baixo peso ao nascer e suas possíveis conseqüências: danos neurológicos evidentes e danos neurológicos não evidentes. Rev Bras. Cresc. Desenv. Hum., 5(112): 96-103, 1995.

MORAES, S. Crianças quem são elas? In: CALLIGARES, C. et al. Educa-se uma criança? Porto Alegre, Artes e Ofício, 1994. p. $175-$ 184.

PARKER, R. G. Corpos, prazeres e paixões. a cultura sexual no Brasil contemporâneo. São Paulo, Best Seller, 1991.

PHAROAH, P.O.D. et al. Prevalence of behaviour disorders in low birth weight infants. Arch. dis. Childhood, 70: 271-274, 1994.

ROMANELLI, G. Mudanças e transições em famílias de camadas médias. Travessia, 9(4): 3234, 1991.

ROUSSOUNIS, S. H.; HUBLEY, P. A.; DEAR, P. R. F. Five - year- follow-up of very low birth weight infants: neurological and psychological outcome. Child Care Health and Dev., 19(1): 45-59, 1993.

SOBOLEWSKI, M. et al. Análise do desenvolvimento neuropsicomotor em recém-nascidos de baixo peso. Pediatria, 18(4): 180-184, 1996.

WALKER, J. The behaviour of 3-year-old children who were born preterm. Child-care, Health and Develop nent,15(5): 297-313, 1989.

WORLD HEALTH ORGANIZATION. Public health aspects of low birth weight. (Technical Report, Series, 217), 1961. 